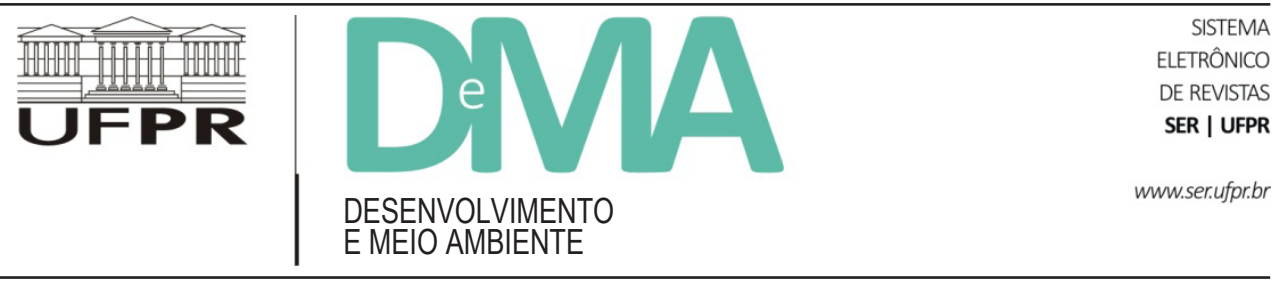

\title{
Segurança alimentar e pesca artesanal: análise crítica de iniciativas na América Latina
}

\section{Food Security and Artisanal Fisheries: Critical Analysis of Initiatives in Latin America}

\author{
Denis HELLEBRANDT ${ }^{1 *}$, Edward H. ALLISON ${ }^{2}$, Anne DELAPORTE ${ }^{1}$ \\ ${ }^{1}$ School of International Development, University of East Anglia, Norwich, Reino Unido. \\ ${ }^{2}$ School of Marine and Environmental Affairs, University of Washington, Seattle, WA, Estados Unidos. \\ *E-mail de contato: d.hellebrandt@uea.ac.uk
}

Artigo recebido em 28 de fevereiro de 2014, versão final aceita em 1 de setembro de 2014.

RESUMO A importância da segurança alimentar é frequentemente mencionada em políticas públicas focadas na pesca artesanal, mas raramente é articulada como objetivo específico. Propõe-se neste artigo abordar a pesca como sistema alimentar e, assim, contribuir para um processo de governança que integre redução da pobreza, sustentabilidade e desenvolvimento humano. Este artigo busca analisar as práticas atuais de governança da pesca artesanal, sob o prisma da segurança alimentar e com foco específico na América Latina. Utilizou-se revisão sistemática dos dados secundários e levantamento detalhado de projetos liderados predominantemente pela sociedade civil em pesca, conservação marinha e desenvolvimento costeiro. Demonstrou-se uma marcada divergência entre planejamento e execução de projetos. Foram identificadas diversas iniciativas que afirmaram ter a segurança alimentar e redução da pobreza entre seus objetivos ( $\mathrm{n}=60$ na amostra global, nove das quais na América Latina). Apesar de haver razão para otimismo, nota-se que predominam iniciativas que adotam a segurança alimentar de forma simplista, ou puramente conceitual. Propõe-se a discussão de mecanismos de avaliação e monitoramento que demonstrem quão efetivas são iniciativas de gestão e desenvolvimento pesqueiro em assegurar o acesso ao pescado e seus benefícios nutricionais para populações dependentes da pesca artesanal.

Palavras-chave: segurança alimentar; nutrição; governança.

ABSTRACT The importance of food security is frequently mentioned in small-scale fisheries policies, but it is seldom articulated as an explicit objective. We propose to approach fisheries as a food system, and by doing so, we seek to contribute to governance processes which integrate poverty reduction, sustainability and development. This paper aims to analyse current discourse and practice in artisanal fisheries, from the perspective of food security and with a specific focus on Latin America. We applied systematic review of secondary data and a detailed survey of initiatives led primarily by the civil society in fisheries, marine conservation and coastal development. We demonstrated a striking divergence between project planning and implementation. Several initiatives which had food security and poverty reduction among their objectives ( $\mathrm{n}=60$ in the global sample, 
nine of which in Latin America) were identified. In spite of reasons for optimism, we observed that interventions which adopted food security in a simplistic manner, or purely at the level of discourse, were predominant. We propose the discussion of mechanisms for monitoring and evaluation which demonstrate the effectiveness of fisheries management and development initiatives in securing the access to resources and their nutritional benefits to fisheries-dependent populations.

Keywords: food security; nutrition; governance.

\section{Introdução}

Ainda que a maior parte das ações dedicadas a promover sistemas pesqueiros resilientes tem se concentrado em tornar pescarias sustentáveis em termos ecológicos e econômicos, a preocupação com as dimensões culturais e sociais do uso sustentável de recursos pesqueiros vem sendo debatida pelos próprios pescadores e por cientistas sociais com enfoque em comunidades pesqueiras (Kooiman et al., 2008; Sharma, 2011). A discussão proposta por estes atores tende a ser considerada de modo limitado e indireto pelos tomadores de decisão, o que levou recentemente a realização de ações coordenadas para estimular a articulação de políticas públicas que incluam efetivamente os anseios e necessidades das populações dependentes da pesca (Bavinck et al., 2005). Tais ações ressaltam a importância da pesca artesanal e de pequena escala em países em desenvolvimento e enfatizam abordagens que incluam modos de vida sustentáveis, segurança alimentar, direitos humanos e bem-estar (Béné et al., 2007; Béné et al., 2010; Béné \& Friend, 2011; Allison, 2011; Allison et al., 2012; Coulthard et al., 2011; Subasinghe et al., 2012). Tais abordagens coalescem em duas amplas iniciativas: as recomendações para promoção da pesca de pequena escala sustentável liderada pela FAO (FAO, 2012) e o programa do WorldFish Centre sobre Sistemas Agrícolas Aquáticos (CGIAR, 2012).

Essas iniciativas, de modo geral, contrapõem-se a uma aliança global mais influente (CEA, 2012), liderada pelo Banco Mundial sob o projeto PROFISH e composta por organizações ambientalistas não governamentais, instituições filantrópicas e indústria pesqueira. Apesar de tal aliança levar em consideração dimensões sociais da reforma de políticas públicas, ela representa um consenso fundamentado em soluções da economia de mercado para a gestão pesqueira e ambiental. Esse consenso não é universal e há preocupações legítimas fora da aliança com a ênfase dada por aquelas parcerias na escala global da gestão de recursos comuns (bens públicos) e nos interesses de atores influentes no consumo de pescado. Teme-se que tal foco tenda a marginalizar os interesses daqueles que têm mais a perder com a generalização excessiva de perspectivas globais, sobretudo as comunidades dependentes de recursos pesqueiros em países em desenvolvimento.

Apesar daqueles envolvidos nessas iniciativas estarem buscando soluções que incluam os anseios do maior número de atores, ao invés de um consenso, há sim um debate intenso sobre a natureza das políticas públicas resultantes desse trabalho (Ratner \& Allison, 2012). Considerando-se que há risco real de que a aliança mais poderosa de interesses ambientalistas e financeiros globais possa predominar sobre preocupações com a dimensão social da sustentabilidade e a economia local, propomos a discussão destes temas. Nosso marco analítico geral baseia-se na representação simplificada das múltiplas dimensões da pobreza (Figura 1).

Este artigo busca analisar as práticas atuais de governança da pesca artesanal, sob o prisma da segurança alimentar e com foco específico na América Latina. A partir do entendimento que a pobreza pode ser abordada em termos de renda, vulnerabilidade e marginalização, identificamos e classificamos iniciativas de acordo com os objetivos e lógica de intervenção conforme relatado pelas próprias organizações. Apresentamos a seguir os conceitos e perspectivas que guiam nossa abordagem.

\section{Marco conceitual}

\subsection{Pesca artesanal e de pequena escala}

Definimos pesca artesanal e de pequena escala como a combinação de práticas complexas, baseadas 


\section{Abordagem multidimensional da pobreza}

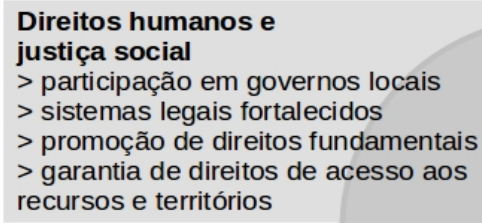

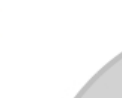

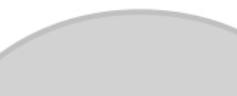

\section{RENDA}

Produção de bases materiais de modos de vida sustentáveis $>$ diversificação da geração de renda > educação e capacitação profissional $>$ provisão de crédito e poupança

$>$ transferência tecnológica

\section{VULNERABILIDADE}

\section{MARGINALIZAÇÃO}

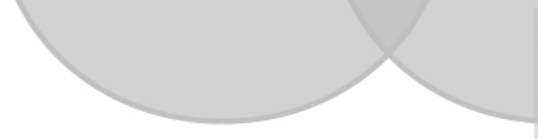

Adaptação e redução de risco > adaptação às mudanças climáticas $>$ preparação para desastres $>$ melhoria de serviços de saúde > provisão de seguro e esquemas > a sobreposição entre círculos indica interação de de proteção social processos determinantes da pobreza. > possíveis intervenções são listadas ao lado de cada dimensão e estão igualmente sujeitas a interações.

FIGURA 1 - Marco analítico para a abordagem multidimensional da pobreza.

FONTE: Modificado de Allison et al. (2011).

na extração de pescado em ambientes aquáticos, com objetivos que vão desde a garantia de subsistência a criação de empresas (Berkes et al., 2001; Johnson, 2006). Ter como ponto de partida uma definição que ressalte a diversidade e dinamismo do conceito nos permite um enquadramento mais adequado da realidade observada em múltiplos contextos. Por outro lado, classificações baseadas primariamente em características físicas (por exemplo, tamanho da embarcação), apesar de provável utilidade para fins burocráticos, tem aplicação necessariamente limitada a contextos específicos.

A fim de evitar excessiva abstração, é possível listar características compartilhadas pela maioria dos sistemas de pesqueiros artesanais e pequena escala: viagens de curta duração (não raro, um dia ou menos), capturas próximas da costa e ausência de refrigeração a bordo ou uso de estruturas rudimentares $-\mathrm{a}$ diversidade de técnicas, materiais empregados e ambientes explorados torna maiores simplificações de pouquíssima utilidade (HLPE, 2014). Há, no entanto, abordagens que argumentam em favor de uma interpretação comum a todos os fenômenos na categoria, incluindo uma generalização da pesca artesanal em escala global (Chuenpagdee et al., 2006). A resultante limitação em termos analíticos é contrabalançada pela relativa simplicidade do conceito que, em princípio, facilita a identificação de problemas e demandas globais e regionais. Independentemente da ênfase da definição adotada, seja na complexidade ou na generalização, reforçamos que o uso de critérios rígidos para descrição da pesca artesanal, apesar de vantagens no âmbito estritamente administrativo, tem limitado valor analítico.

Inclusive, vale ressaltar que a diversidade na pesca artesanal tende a ser subestimada pela atenção despro- 
porcional dada à comparação entre pesca artesanal e industrial. Tal tendência, intencionalmente ou não, reproduz a aparente ruptura causada pelos conflitos entre pesca de pequena e grande escala - conflitos estes que, sem sombra de dúvida, resultam em impactos concretos e amplamente documentados (Charles, 1992; Bavinck, 2005). Mesmo que a discussão de tais conflitos seja justificada e a comparação de escalas contribua para que entendamos as diferenças entre categorias (Berkes et al., 2001), corre-se o risco de subestimar características essenciais da atividade pesqueira, sobretudo da pesca artesanal e de pequena escala.

A revisão rigorosa da abordagem comparativa demonstra que a valorização excessiva da diferenciação entre categorias impede que se considere nuances e fluxos entre formas de organização da pesca (Johnson, 2006). Por exemplo, pescadores artesanais podem formar parcerias ou buscar trabalho na pesca industrial em resposta à necessidade ou oportunidade - ainda, esse fluxo pode inverter-se, ou resultar na formação de escalas intermediárias ("semi-industrial", Haimovici et al., 2006) com fluxo de capital humano e financeiro tanto de categorias artesanais como industriais (Allison \& Ellis, 2001). Por fim, o excesso de importância conferida à polarização entre categorias pode levar a uma visão simplificadora de que "pequeno" ou "artesanal" equivalem a formas ideais baseadas na tradição e respeito pelos recursos compartilhados. Por mais atraente que seja a noção de que atividades de pequena escala são plataformas ideais para a sustentabilidade, uma abordagem crítica é necessária (Blaikie, 2006), com base numa perspectiva que reconheça a complexidade intrínseca em sistemas pesqueiros.

No que diz respeito à gestão de recursos pesqueiros, adotamos a distinção entre manejo e governança proposta por Béné \& Neiland (2006). Entende-se por manejo a "implementação de decisões e ações de acordo com regras", componente integral dos sistemas analisados e relevante, por exemplo, quando tratamos da aplicação de limites no volume capturado ou da vigilância de territórios de acesso restrito. Porém, o foco da discussão neste artigo está na governança, nos "mecanismos e processos nos quais poder e capacidade de decisão são alocados entre diferentes atores" (Béné \& Neiland, 2006, p. 1112). A ênfase sobre a distinção entre aplicação de regras e processos de governança é necessária para complementar de modo coerente nossa abordagem da gestão de recursos pesqueiros. Nosso marco conceitual pressupõe que além dos modos de vida serem afetados por instituições (por exemplo, na alocação de acesso aos recursos), também o contexto institucional é influenciado pelos modos de vida (por exemplo, regras podem ser contestadas por meio de protesto, participação ou criação de fóruns de decisão e implementação alternativos) (Jentoft, 2004). Essa relação complexa entre gestão e modos de vida é composta, além das óbvias regras formais, por questões de valores e legitimidade, a chamada "dimensão normativa" das instituições (Jentoft et al., 1998). Reconhecemos a relevância da dimensão regulativa da gestão, mas questões sobre os elementos ideais para formação de instituições (Ostrom et al., 1999) ou a preocupação com modos de adaptação institucional ao ecossistema (Wilson, 2002) são secundárias no contexto desse artigo.

\subsection{Pobreza}

Percebe-se uma clara evolução na definição do conceito de pobreza em décadas recentes: além da atenção original no consumo e renda e falta de acesso à saúde, saneamento, alimentação e moradia, definições mais elaboradas passam a incluir conceitos de agência, capital humano e capacidades (Sen, 1981) e relações entre pobreza e sustentabilidade ambiental (Bebbington, 1999). A inclusão de múltiplas dimensões no conceito de pobreza obteve consenso, sobretudo através de seu uso como base para a formulação do Índice de Desenvolvimento Humano (IDH) pelo Programa das Nações Unidas para o Desenvolvimento (PNUD) (Macfadyen \& Corcoran, 2002; Allison \& Horemans, 2005).

Apesar do reconhecimento da complexidade do conceito, a natureza quantitativa de abordagens como a adotada no IDH exclui elementos subjetivos da pobreza. Tal característica resulta numa perspectiva que, não obstante sua utilidade segue, todavia, incompleta. Respondendo a esta demanda, observam-se propostas que focam especificamente na percepção dos pobres sobre seu modo vida e contexto (Narayan et al., 2000) e buscam expandir e refinar o conceito de pobreza ao adicionarem dimensões de bem-estar (Coulthard et al., 2011) e direitos humanos (Allison et al., 2011). 
Portanto, a abordagem multidimensional da pobreza adotada nesse artigo está embasada num campo consolidado e reflete o desenvolvimento corrente do conceito, tanto numa perspectiva global como no caso específico da pesca. Observações sobre o caráter multidimensional da pobreza em comunidades pesqueiras são relativamente recentes, com a maioria das análises empíricas publicada após 2000 (Macfadyen \& Corcoran, 2002), e a consolidação de um marco conceitual especificamente aplicado à pesca artesanal e de pequena escala ainda em andamento (Allison et al., 2006, Béné \& Friend, 2011). A dimensão material e da renda apresenta desafios significativos para medição ou estimativa da pobreza, mas do ponto de vista conceitual é de relativa simplicidade se comparada à vulnerabilidade e marginalização. Assim sendo, exploramos a seguir diferentes perspectivas sobre estas dimensões, antes de concluir o detalhamento do conceito de pobreza.

Há considerável divergência nas definições de vulnerabilidade (Adger, 2006), sobretudo devido à diferentes posições epistemológicas que predominam em ramos diversos das ciências naturais e sociais (Fussel, 2007). Entre iniciativas de integração de perspectivas, destaca-se a proposta de Turner et al. (2003), pelo foco no uso de recursos naturais e pela inclusão explícita de elementos sociais em seu marco conceitual. Nesse caso, vulnerabilidade é entendida como a susceptibilidade de um sistema sofrer danos ou perturbações causados pela exposição a choques intensos ou ao impacto negativo de processos de longo prazo (Turner et al., 2003, p. 8074). A vulnerabilidade seria função não somente da exposição e sensibilidade aos choques e processos de longo prazo, mas também determinada pela função de instituições no controle do acesso aos recursos naturais (Béné, 2009), pela diversidade de estratégias adotadas em reação às perturbações e pela capacidade do sistema resistir ao impacto das mudanças (Allison et al., 2009).

Complementando esta linha associada à sustentabilidade e uso dos recursos, temos enfoques que buscam entender relações causais entre choques, risco e pobreza. Nessa perspectiva, vulnerabilidade pode inclusive ser definida tanto como reflexo direto da intensidade da pobreza, como sendo sua causa fundamental (Dercon, 2005). Esse entendimento da vulnerabilidade apoia-se em extenso trabalho de pesquisa e implementação de programas de desenvolvimento, cujas evidências sugerem mecanismos específicos pelos quais riscos e choques podem ser causas da pobreza, a saber: dependência de estratégias de baixo risco, porém também baixo retorno (seja este renda ou alimento) e baixa diversificação dos modos de vida e perda total ou parcial de meios de produção (Dercon, 2005; Ellis, 2005; Macfadyen \& Corcoran, 2002).

No que diz respeito à marginalização, tomamos como ponto de partida os anos 60 , momento em que o marco conceitual dominante coloca a exclusão do mercado de trabalho entre as causas fundamentais da pobreza (de la Rocha et al., 2004). Nas décadas seguintes, avanços tanto nos aspectos empíricos como teóricos demonstraram que a falta de mecanismos adequados de proteção social e baixos salários, em situações de plena inclusão no mercado de trabalho formal, figuravam proeminentemente entre as causas da pobreza (Oliveira, 1972). Como resultado, estabeleceu-se uma noção mais elaborada da relação entre marginalização e pobreza, considerando processos mais sutis de exclusão e com maior atenção para o papel do trabalho informal e redes sociais (Lomnitz, 1988). Estratégias e modos de vida construídos pelos pobres com objetivo de resistir e superar a condição marginalidade passaram então ao centro da discussão, sobretudo no contexto urbano e de intensos movimentos de migração e imigração (Portes \& Roberts, 2005; Portes, 2010).

Uma análise teórica capaz de revelar toda a complexidade do conceito de pobreza foge do objetivo deste artigo. Nesta breve revisão, chamamos atenção para elementos essenciais à compreensão do conceito de pobreza: a tendência observada em décadas recentes de inclusão gradual da perspectiva das populações pobres na construção da teoria e o reconhecimento do papel da vulnerabilidade e de processos de inclusão e exclusão social como determinantes da pobreza. Nessa linha enquadramos nossa análise, partindo da identificação das conexões entre elementos materiais e relações sociais e articulando sua contribuição para o entendimento da pobreza em comunidades dependentes da pesca.

A abordagem crítica e ciente da complexidade do conceito torna possível entender que a pobreza em comunidades pesqueiras não é necessariamente causada pela sobrepesca (Béné, 2003). A diminuição de renda 
causada por quedas no volume ou valor do pescado capturado pode figurar, logicamente, entre as causas da pobreza em uma determinada comunidade - no entanto, mesmo que a situação se reverta, o estado de pobreza permanecerá caso as demais dimensões não demonstrem melhora (Béné \& Friend, 2011). Em outras palavras, de pouco servirá o aumento de renda na venda de pescado, se a comunidade seguir sofrendo com desnutrição e doenças devido à falta de atendimento básico de saúde, ou ainda se a marginalização nos processos políticos limitar sua capacidade para demandar melhorias em serviços públicos.

\subsection{Segurança Alimentar e Nutricional}

Em sua forma mais amplamente utilizada, segurança alimentar e nutricional (SAN) é definida como "a situação na qual todas as pessoas, em todos os momentos, têm acesso em termos físicos, sociais e econômicos a alimentos nutritivos, seguros e em quantidade suficiente para garantir as necessidades nutricionais e preferências alimentares que possibilitem uma vida ativa e saudável." (World Food Summit 1996, citado em Barret, 2010). Tal conceito explicita o caráter dinâmico da SAN (ênfase na capacidade de resposta a choques na disponibilidade e acesso aos alimentos) e aponta claramente que a disponibilidade de alimentos garante apenas parcialmente a "vida ativa e saudável".

De fato, em discussões mais aprofundadas da SAN observa-se a articulação de no mínimo três componentes: disponibilidade, acesso e utilização (Rosegrant \& Cline, 2003; Pinstrup-Andersen, 2009; Godfray et al., 2010). A existência de alimentos disponíveis à população é o requerimento mais básico, porém não suficiente para garantia da SAN. A forma como diferentes grupos acessa esses alimentos é que determina em grande parte se o objetivo final da SAN poderá ser atingido. Mecanismos diversos, regidos por tradição, normas sociais ou regras formais, afetam a capacidade de acesso a alimentação saudável, sobretudo entre grupos vulneráveis (Sen, 1981).

Uma vez assegurado o acesso, resta ainda se estabelecer como o alimento será utilizado pelas pessoas, pois condições de estocagem e formas de preparo influenciam na contribuição final da alimentação para a saúde dos indivíduos. Condições sanitárias desfavoráveis podem causar doenças que limitam a absorção de nutrientes, ou estes podem ser eliminados no processamento dos alimentos, levando a insegurança alimentar mesmo que disponibilidade e acesso equitativo sejam garantidos (Bhutta et al., 2013). Por fim, é importante considerar a escala na qual se aplica o conceito de SAN, visto que segurança alimentar no nível da comunidade e domicílio não implica necessariamente segurança alimentar no nível individual (por exemplo, a distribuição de alimentos ricos em proteína pode ser desigual entre homens, mulheres e crianças) (Pinstrup-Andersen, 2009).

Uma vez estabelecidos os principais aportes teóricos e a diversidade de perspectivas consideradas em nosso marco conceitual, passamos a descrição da metodologia.

\section{Métodos de busca, seleção e análise das iniciativas}

O levantamento de iniciativas em escala global foi realizado de junho a dezembro de 2012 e baseou-se em questionários por e-mail, buscas na $w e b$, entrevistas semiestruturadas (por telefone ou em contato direto). Buscamos identificar iniciativas no âmbito da pesca e aquacultura cujos objetivos inclú́ssem tanto conservação (gestão de recursos, preservação de espécies, conservação de biodiversidade ou habitats) como desenvolvimento (redução da pobreza, empoderamento, redução da vulnerabilidade e-segurança alimentar). Além de dados identificadores das iniciativas, coletamos informações detalhadas sobre evidências de impacto (por exemplo, relatórios de atividades, avaliações externas formais e testemunhos de pessoas beneficiadas pelas ações). Buscamos especificamente por iniciativas, em países em desenvolvimento ou economias em transição e por casos que incluíssem ações práticas de implementação de políticas ou ativismo, sendo excluídos casos de ações cujo objetivo principal era pesquisa ou apoio/consultoria (veja anexo para detalhes dos procedimentos adotados).

A fase inicial do levantamento resultou na identificação de 88 iniciativas. A análise mais aprofundada desse conjunto levou a exclusão de 28 casos nos quais foi 
verificado que a iniciativa enquadrava-se nos seguintes critérios:

> não apresentava foco explícito em países em desenvolvimento ou economias em transição;

$>$ tinha como objetivo primário ou exclusivo a pesquisa acadêmica, ao invés de ações práticas - interpretadas como intervenções de natureza ambiental, econômica ou política;

$>$ não apresentavam objetivos ou estratégias com foco explícito na redução da pobreza e ou segurança alimentar.

Portanto, o conjunto final de iniciativas incluídas na análise foi formado por 60 casos, dos quais nove atuavam na América Latina. Buscamos obter uma amostra ampla e representativa de iniciativas no âmbito da pesca e aquacultura e conservação, incluindo desde projetos de grande escala liderados por organizações intergovernamentais e ONGs ambientalistas internacionais, até projetos de pequena escala envolvendo organizações da sociedade civil, de governos locais e setor privado. Nosso objetivo não foi identificar a totalidade das iniciativas atuando na interface conservação e desenvolvimento ao redor do mundo, e tampouco buscamos uma amostra que permitisse análises estatísticas do setor. Por outro lado, identificamos fontes diversas e realizamos buscas de forma exaustiva dentro do tempo limitado disponível para a coleta, e aplicamos nossos critérios com rigor e transparência a fim de evitar uma amostra tendenciosa (veja anexo para detalhes dos procedimentos adotados).

O objetivo geral da análise aqui apresentada não foi realizar uma avaliação da efetividade das iniciativas, mas sim identificar as formas como estas adotaram metas de redução de pobreza e promoção da SAN. Mais especificamente, buscamos verificar se as metas alegadas permaneceram apenas articuladas como conceitos ou foram traduzidas em aplicações práticas.

Do ponto de vista empírico, a análise incluiu a compilação de uma matriz de dados com variáveis descritivas (contendo dados básicos de identificação de cada iniciativa) e categóricas (contendo a codificação de elementos nos planos e ações de cada iniciativa que correspondessem às múltiplas dimensões da pobreza em nosso marco conceitual). Além desse elemento descritivo, temos a análise crítica dos dados disponíveis, na qual exploramos a forma como os conceitos de pobreza e SAN foram articulados na construção de seus programas e discutimos sua implementação no contexto de ações integradas de gestão sustentável de recursos pesqueiros, redução de pobreza e promoção da SAN. O presente artigo concentra-se neste componente crítico, utilizando a análise das iniciativas como base para a discussão mais ampla de conceitos, suas aplicações no contexto da pesca artesanal e as contribuições do Estado e sociedade civil para maior efetividade destas intervenções.

\section{Características das iniciativas selecionadas}

A descrição apresentada a seguir sintetiza dados coletados e estruturados originalmente durante esse estudo - referências são dadas nos raros casos em que há documentos disponíveis online. A tabela 1 apresenta as principais características das iniciativas analisadas e inclui links atualizados para as fontes de informação online (sempre que possível websites institucionais).

Foram identificadas iniciativas em nove países da América Latina, representando aproximadamente 25\% da amostra global composta por intervenções em 35 países em desenvolvimento. Seguindo a classificação de acordo com o marco multidimensional da pobreza, observamos que a maioria das iniciativas desenvolveu intervenções na dimensão da renda, por vezes integrando também ações nas dimensões de marginalização e vulnerabilidade, conforme relatado em detalhe a seguir.

Houve um predomínio de intervenções lideradas por organizações da sociedade civil (sobretudo organizações não governamentais - ONGs). Os setores privado e governamental apenas figuraram indiretamente, em parcerias com a sociedade civil - o caso de organizações intergovernamentais (Programa da IUCN na América Central e México, e UNDP no sistema da corrente de Humboldt) representam instâncias especiais caracterizadas pela ampla escala geográfica de atuação. Ainda assim, ambas as iniciativas tratam-se de intervenções baseadas na colaboração entre atores governamentais e comunidades.

No caso da UNDP, a iniciativa inclui a parceria com o setor privado e organizações de pescadores no Chile e Peru, com estrutura de gestão específica dedicada à coordenação e integração do trabalho entre atores (HCLME, 2012). Similarmente, o programa da IUCN ba- 


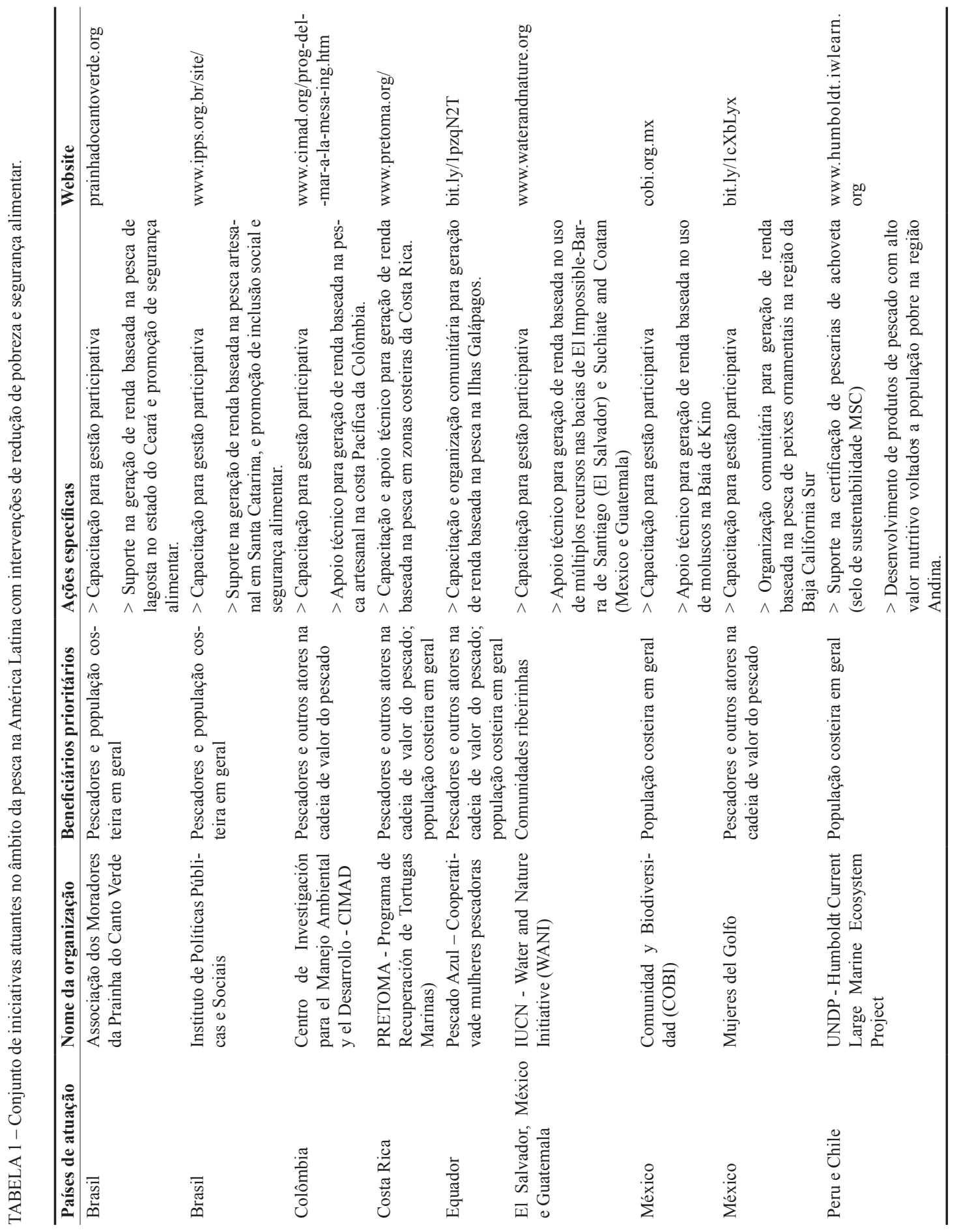


seia-se, sobretudo na facilitação de ações integradas entre associações comunitárias e agências governamentais e não governamentais envolvidos no desenvolvimento na zona costeira. Todas as demais iniciativas são lideradas por ONGs ou cooperativas com base e atuação local, ou seja, seus membros têm origem em uma comunidade ou grupo de municípios relacionados a uma zona geográfica ou ecológica limitada, que também delimita seu foco de atuação - por exemplo, lagoas costeiras no sul do Brasil no caso do IPPS, ou pescaria de moluscos na Bahia de Kino, México, no caso da COBI.

O eixo central da totalidade das intervenções na América Latina foi a gestão de recursos pesqueiros seja de forma direta, levando a ações de capacitação e suporte a gestão participativa, ou indireta, como base de intervenções voltadas a certificação de pescarias, organização de cooperativas e comércio de pescado (Tabela 1). Nota-se que as iniciativas selecionadas buscaram ativamente conectar a gestão e uso sustentado de recursos com a redução da pobreza através de ações de melhoria da renda, de acesso aos meios de produção, e valorização do capital humano associado.

A complexidade de ações integradas de gestão de recursos e redução da pobreza são exemplificadas pelas cooperativas "Mujeres del Golfo" (México) e Pescado Azul (Equador). Em ambos os casos, a formação das cooperativas responderam não somente à necessidade de geração de renda, mas fundamentaram-se na inclusão de atores locais na gestão participativa dos recursos pesqueiros, além do empoderamento de mulheres. A predominância do foco na dimensão da renda é apenas aparente, já que há elementos inequívocos de redução da vulnerabilidade, através do uso sustentável de recursos e ambientes particularmente sensíveis a choques (peixes ornamentais no México e Ilhas Galápagos no Equador). Igualmente, o combate à marginalização é ressaltado pelo papel central das mulheres em ambas inciativas, justificado explicitamente por seu papel chave na promoção da segurança alimentar no caso do Equador (UNDP, 2012).

O público-alvo das iniciativas incluiu em todos os casos pescadores e comunidades ribeirinhas, que é a população beneficiária esperada dada a natureza das organizações e critérios de seleção deste estudo. Outros aspectos do público-alvo, porém, demonstraram a diversidade e alcance das iniciativas analisadas. Primero, como apresentado acima, dois casos representam organizações exclusivamente dedicadas à capacitação e inclusão de mulheres em posições autônomas na cadeia de valor do pescado. Segundo, várias iniciativas incluem entre seus beneficiários a população costeira em geral, explicitamente buscando estender os benefícios em termos de segurança alimentar ou inclusão social além daqueles diretamente envolvidos com a pesca.

As duas iniciativas brasileiras são emblemáticas desse tipo de intervenção ampla e inclusiva. No caso da Associação dos Moradores da Prainha do Canto Verde tem-se talvez o mais forte componente local entre as iniciativas, tanto na formação da organização como na sua atuação. O papel da Associação abrange desde a facilitação do acesso dos moradores aos serviços públicos (por exemplo, na ação coordenada com o governo federal brasileiro para a implementação de programas de alfabetização e inclusão digital) até iniciativas próprias como a promoção do turismo ecológico, cultura de algas e agricultura familiar, utilizando uma mescla de recursos financeiros e humanos próprios e de parceiros estatais e privados. Subjacente a esta miríade de ações, está a não menos relevante promoção da participação ativa de representantes locais na gestão da pesca lagosta no litoral do estado do Ceará.

O Instituto de Políticas Públicas e Sociais (IPPS) atua de forma similar, com enfoque no sistema pesqueiro e agrícola em estuários e lagunas costeiras no sul do Brasil. Assim como no caso anterior, o trabalho do IPPS é caracterizado pela diversidade de ações e objetivos explícitos de promoção da segurança alimentar, empoderamento das comunidades locais e coordenação de ações com atores governamentais. Ainda, observa-se uma estruturação clara das intervenções buscando a diversificação dos modos de vida (por exemplo, na capacitação profissional tanto em atividades relacionadas à pesca como fora da atividade) e a integração de ações baseadas na agricultura familiar na promoção da SAN.

Em contraste com iniciativas de enfoque amplo e integrador temos casos em que a conservação da biodiversidade é o elemento determinante das ações. As intervenções promovidas pelo CIMAD na Colômbia e PRETOMA na Costa Rica tipificam esta abordagem. Casualmente, ambas têm na conservação de tartarugas marinhas e seu habitat o objetivo central das ações. Nes- 
tes casos pressupõe-se que o apoio à geração de renda nas comunidades pesqueiras resulte em diminuição da pressão sobre a espécie ameaçada e ecossistema como um todo. Apesar da contribuição indireta à redução da vulnerabilidade através da conservação ambiental e da relativa promoção da inclusão social, tais iniciativas baseiam-se numa estratégia de redução da pobreza limitada. A ênfase na participação no mercado como mecanismo central de empoderamento e ausência de consideração sobre vulnerabilidade social e SAN contrastam com iniciativas descritas anteriormente.

\section{Potenciais limitações da análise}

A capacidade de integração de ações, especialmente a relação entre gestão sustentável de recursos pesqueiros e redução de pobreza ou segurança alimentar, pode, na verdade, estar limitada a conceitos, mas não a aplicação destes. Verificamos as afirmações disponíveis de forma exaustiva, incluindo triangulação entre diferentes fontes, porém somente uma avaliação individual e aprofundada de cada caso poderia minimizar ainda mais quaisquer incertezas. Existe, no entanto, a chance real de que incertezas permaneceriam de qualquer forma, exceto se talvez testemunhássemos pessoalmente as atividades de cada iniciativa. O escopo de nossa análise não incluía esse nível de detalhe, e acreditamos que fomos suficientemente cautelosos na aplicação de critérios de seleção, justamente com a finalidade de evitar a inclusão de casos que apresentassem obstáculos à verificação de suas ações.

Não obstante, há que se reconhecer a disponibilidade limitada de informações na maioria dos casos analisados. São raros os casos em que as organizações adotam processos formais de avaliação e monitoramento, ou nos casos em que eles existem, os dados não são publicados ou acessíveis externamente. Nos casos analisados na América Latina, tivemos acesso a informações relativamente detalhadas, porém em nenhuma instância obtivemos acesso ao resultado de avaliações formais. Essa limitação não nos surpreende, visto que os requerimentos de tais avaliações em termos de custo e capacidade técnica os tornam proibitivos, sobretudo no caso de iniciativas de pequena escala como as que predominam no conjunto analisado.

Finalmente, há o risco de que análises baseadas em dados secundários favoreçam a inclusão de organizações internacionais, cujas ações recebem maior exposição em mídias diversas e reconhecimento por atores influentes na pesquisa e ativismo. É importante dar atenção a tal ressalva, visto que iniciativas locais e de menor escala podem existir por anos sem registrar presença fora de seu contexto de atuação. Essas iniciativas operam estruturas informais que tendem a ser particularmente efetivas na mobilização popular e promoção de inclusão social, no entanto são, por natureza, difíceis de documentar e avaliar (Pinstrup-Andersen, 2013).

\section{Lacunas e pontos para reflexão na implementação das intervenções analisadas}

Identificamos os seguintes pontos como aspectos estratégicos das intervenções, cuja implementação requer maior reflexão entre as organizações responsáveis: $>$ a atenção dada a promoção de segurança alimentar e redução de má alimentação de forma geral é indireta e limitada na maioria das intervenções - tal observação é corroborada por avaliações sistemáticas recentes, que inclusive incluem outros sistemas de produção (Masset et al., 2012);

$>$ as iniciativas analisadas não incluem implementação de programas de compartilhamento de estoques e capturas (catch-share) ou de direitos territoriais exclusivos - no entanto, deve-se ressaltar que áreas protegidas que seguem o modelo de reservas extrativistas combinam ações de desenvolvimento e inclusão social com gestão baseada em territórios e arranjos produtivos tradicionais; $>$ apesar de serem representados por um conjunto reduzido em comparação ao universo total de intervenções, os casos na América Latina enfocaram públicos diversos, incluindo ações especificamente destinadas à inclusão de mulheres e atores diversos ao longo da cadeia de valor do pescado;

$>$ intervenções que atuam na organização da comercialização do pescado aparentam ter impacto limitado nos mercados locais, já que tendem na totalidade a conectar produtores locais com compradores ou intermediários 
em mercados globais - vide a atenção dada a certificação com selos de sustentabilidade que permitem a inserção de produtos em mercados na Europa e Estados Unidos.

\section{Conexões entre gestão pesqueira}

sustentável, redução de pobreza e segurança alimentar e nutricional

É notável a quase completa ausência de elementos de segurança alimentar e nutricional na maioria das iniciativas analisadas (tendência ainda mais marcada na amostra global), motivo pelo qual propomos aprofundar a discussão desse tema em particular. Partimos do entendimento que ações integradas de redução de pobreza e gestão sustentável de recursos naturais contribuem direta e indiretamente para melhoria da nutrição e saúde em populações pobres e vulneráveis. Para tal, nos valemos da distinção entre ações diretas e indiretas (Black et al., 2008) (Figura, 2). Ações diretas buscam maximizar a ingestão e absorção de nutrientes pelos indivíduos ao mitigar efeitos da dieta inadequada e doenças. Tais ações

\section{Relações entre pobreza e segurança alimentar e nutricional}

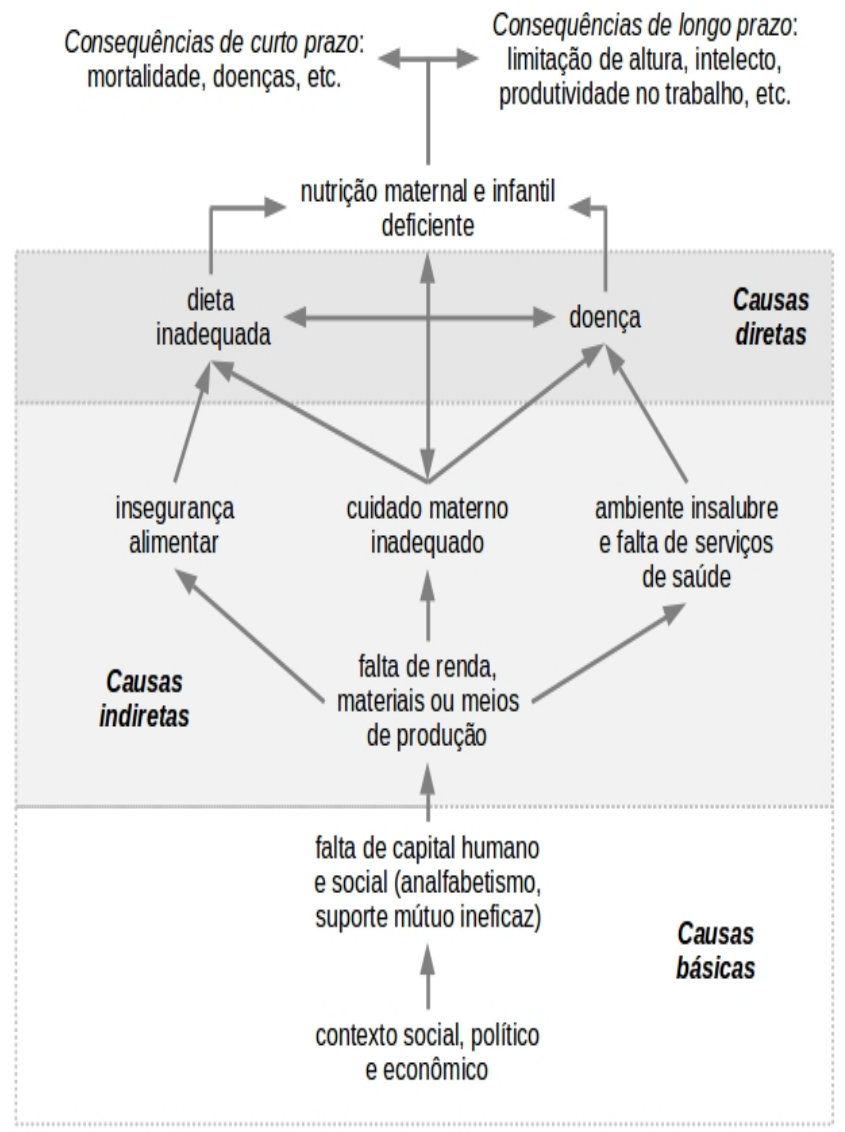

FIGURA 2 - Marco analítico para avaliação das relações entre pobreza e segurança alimentar e nutricional.

FONTE: Adaptada de Black et al. (2008) 
geralmente estão associadas a projetos de longo prazo liderados por organizações governamentais, ou a reações a desastres ou emergência, nos quais também se observa a participação de organizações da sociedade civil. É no caso das ações indiretas que se percebe a liderança das organizações da sociedade civil mais claramente em projetos focados em educação e justiça social (questões raciais, de gênero, etc.), cujo objetivo é combater as causas indiretas e básicas da insegurança alimentar e má nutrição.

É neste contexto, portanto, que se inserem as iniciativas aqui analisadas. Idealmente, as intervenções direcionadas à capacitação de pescadores e comunidades para gestão compartilhada teriam efeitos significativos sobre parte das causas indiretas (potencial melhoria do capital humano e social dos grupos envolvidos em processos participativos de governança), assim como sobre as causas básicas de insegurança alimentar e nutricional ao contribuírem para um contexto político e econômico mais positivo. Ainda, se as intervenções visando uso e gestão sustentável dos recursos integrarem efetivamente ações de geração de renda e de maximização dos benefícios da cadeia de valor do pescado para pescadores e comunidades associadas, nós teríamos efeitos abrangentes sobre a dimensão material da pobreza e, consequentemente, o máximo potencial de impacto sobre as múltiplas causas de má nutrição.

Mesmo que a integração de ações seja efetiva e o desempenho das intervenções seja o máximo possível, dificilmente iniciativas isoladas da sociedade civil seriam suficientes para garantir o impacto efetivo sobre a nutrição e saúde nos sistemas pesqueiros. Há limitações devidas à complexidade e rápida transformação destes sistemas numa economia globalizada, as quais requerem capacidade de organização e nível de influência para atuação sobre as causas básicas e indiretas de insegurança alimentar que estão aquém da maioria das iniciativas existentes, sobretudo das atuantes em escala local. Os desafios, tanto na execução de projetos como na própria análise do tema, são substanciais, o que serve de alerta para propostas ambiciosas baseadas na integração de intervenções. Ainda assim, acreditamos que seja válida a discussão de uma abordagem das relações entre segurança alimentar e pesca que explore os diferentes elementos do sistema alimentar e especificamente busque esclarecer os diferenciais de poder e acesso a recursos que permeiam as relações entre elementos. Tal abordagem (Figura 3) pode ser tomada como um ponto de partida para a identificação de elementos-chave para o planejamento e avaliação de intervenções.

Por fim, há também que se considerar diferentes pontos de vista sobre governança nesse contexto (Gillespie et al., 2013), o que nos leva a indagar quais são os papéis de atores governamentais e da sociedade civil na promoção da segurança alimentar e nutricional. Na seção a seguir, avaliamos criticamente diferentes perspectivas sobre modos de colaboração entre Estado e sociedade, baseando a discussão num breve histórico das políticas públicas brasileiras no campo da segurança alimentar e nutricional.

\section{Segurança alimentar, políticas públicas $e$ sociedade civil}

Adotamos nesse ponto um marco conceitual que entende a má alimentação e nutrição como fenômeno social e propõe a abordagem crítica de políticas públicas e iniciativas da sociedade civil como meio mais eficaz de garantia do direito à alimentação (Castro, 2001). Em consonância com nossas análises anteriores, o argumento resultante enfatiza a necessidade de integração de iniciativas de promoção da segurança alimentar, de tal modo que diferentes aspectos da alimentação sejam incluídos: desde a produção à disponibilidade de alimentos, passando pelo acesso, cultura e impactos na saúde pública.

Tomando o caso do Brasil como exemplo, observa-se que o desempenho do governo na promoção da segurança alimentar foi até o início da década de 90, definido por ações pontuais e desarticuladas (Pinheiro $\&$ Carvalho, 2010). Foi justamente devido à iniciativa de uma organização da sociedade civil em 1993 (IBA$\mathrm{SE}$ ), que uma abordagem política e integradora do tema passou a definir políticas públicas brasileiras. Apesar de tal mudança, a ênfase das ações governamentais recaiu sobre o desenvolvimento econômico, restando a sociedade civil organizar-se e assumir papel central na manutenção do debate e formulação de iniciativas. A tendência histórica de políticas e ações desarticuladas e de baixa efetividade manteve-se (Silva, 1995). 


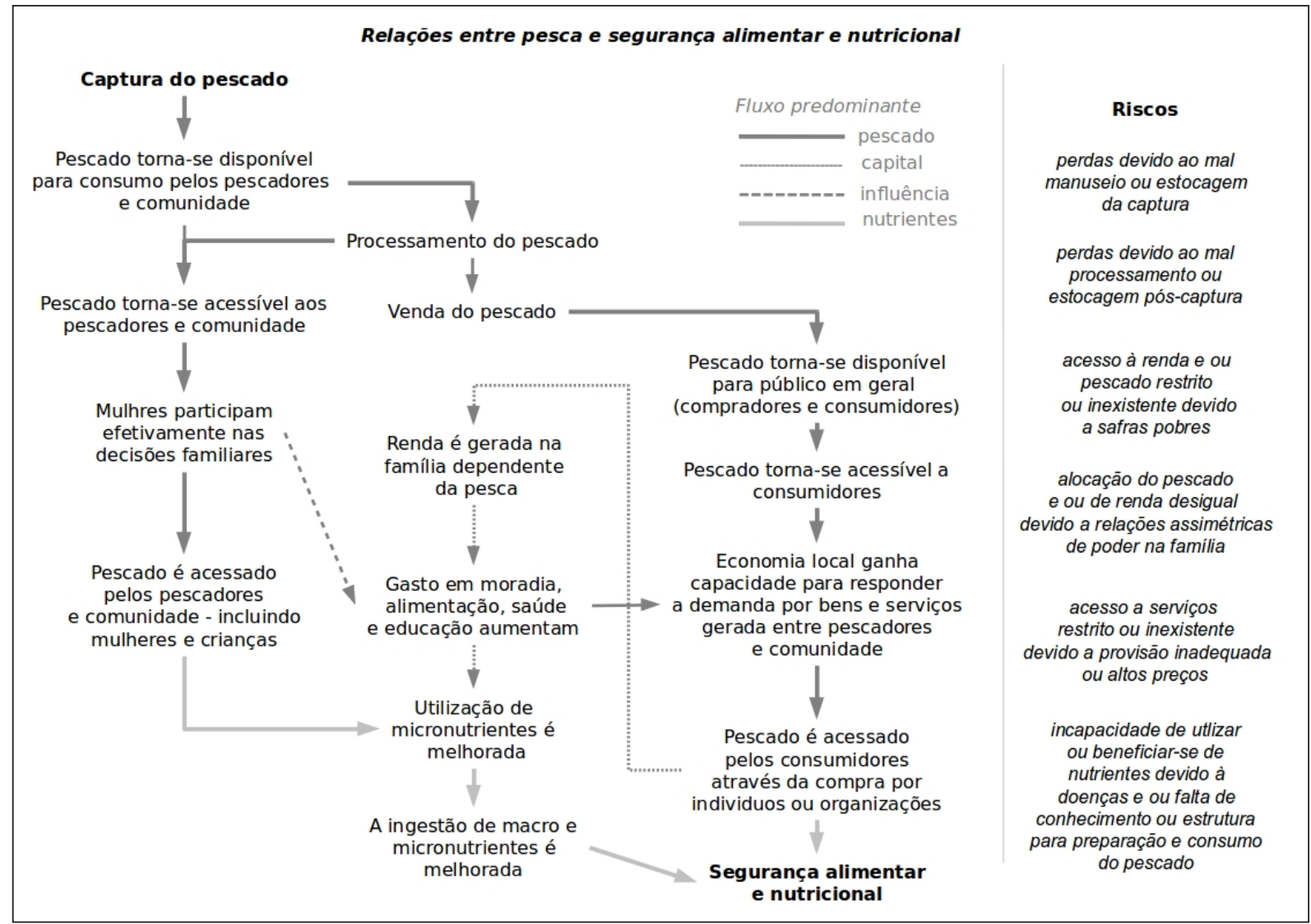

FIGURA 3 - Representação das relações entre pesca e segurança alimentar e nutricional. Na parte central da figura estão representados os elementos e fluxos no sistema e na coluna à direita estão indicados os principais riscos correspondentes às etapas sucessivas que vão da captura do pescado ao impacto na segurança alimentar e nutricional.

FONTE: os autores, presente estudo.

Em 1999, após uma profunda reorganização dos programas e instituições governamentais, foi implementada a Política Nacional de Alimentação e Nutrição (PNAN). O debate realizado ao longo da década influenciou esse novo marco legal de forma decisiva, reafirmando a obrigatoriedade de políticas públicas integradoras e, sobretudo, conferindo papel central ao direito humano fundamental à alimentação. A partir desse momento, o governo brasileiro investiu na implementação de políticas de transferência de renda, que gradualmente passaram a ter a segurança alimentar como objetivo principal, culminando em, 2003 no Programa Fome Zero e na reinstituição do Conselho Nacional de Segurança Alimentar e Nutricional que havia sido extinto em 1995.

O contexto atual, no caso brasileiro, é definido tanto pela retomada do papel central do Estado na promoção da segurança alimentar e nutricional, assim como pelo resgate de plataformas de debate e oportunidades de participação da sociedade civil na discussão de políticas públicas. Após uma década de implementação, as evidências sobre efetividade dos programas brasileiros de transferência condicional de renda são inequívocas, especificamente no que diz respeito ao impacto sobre a nutrição e saúde pública (Arruda \& Arruda, 2007). 
A análise desse contexto nos permite um entendimento mais amplo do papel da sociedade civil em iniciativas de combate à pobreza e promoção da segurança alimentar. Nos anos 1990, o modelo político e econômico brasileiro era determinado pela participação mínima do Estado e pela valorização do papel da sociedade civil na promoção do bem-estar público, incluindo a segurança alimentar e nutricional de populações pobres. Porém, o breve histórico apresentado acima demonstra que o governo teve dificuldades em constituir instituições que possibilitassem esse arranjo efetivamente. Foi somente após a revisão dos objetivos políticos e do modelo de participação do governo e da sociedade civil que se pôde observar a criação de políticas públicas e ações efetivas de segurança alimentar e nutricional.

Esta discussão é de extrema relevância para a análise proposta no presente trabalho. Partimos do pressuposto que, considerando a diversidade de iniciativas e crescente envolvimento da sociedade civil no combate à pobreza e promoção da segurança alimentar no âmbito da pesca, aquacultura e conservação de recursos associados, justificava-se avaliar o desempenho de tais iniciativas. Porém, é de crucial importância que abordemos essa avaliação de forma crítica. Sobretudo, é importante evitar o salto direto da constatação de relativa ausência de ações efetivas para a proposta de maior participação da sociedade civil na provisão da nutrição e saúde pública.

Apesar de aparentemente lógica, tal conclusão assume implicitamente que a lacuna nas ações de garantia de segurança alimentar deve ser assumida pela sociedade civil. A necessidade de participação de atores não governamentais na discussão e implementação de políticas públicas é indiscutível - formam um dos elementos fundamentais do que Gillespie et al. (2013, p. 553) chamam de "ambiente propício" ("enabling environment") para o desenvolvimento de políticas de segurança alimentar. Porém, a forma como sociedade civil e Estado compartilham responsabilidades e, assim, definem suas contribuições, depende do marco político e econômico adotado. Se o objetivo for a retração gradual do estado da provisão de bem-estar e saúde pública, então se justifica uma maior e mais direta participação da sociedade civil nesse âmbito.

Por outro lado, se se entende que pertence ao Estado a responsabilidade de promover a saúde pública de populações pobres através da garantia da disponibilidade, acesso e utilização de alimentos, a participação da sociedade civil toma forma distinta (Nascimento, 2009; Pinheiro \& Carvalho, 2010; de Schutter, 2012). Ao invés de realizar funções que devem ser por princípio assumidas pelo Estado, a contribuição de atores não governamentais passa a priorizar iniciativas, tais como mobilizar interesse público, efetivar a representação de populações pobres na formulação de políticas públicas, colaborar na implementação de ações com o governo e implementar mecanismos participativos de avaliação destas ações.

\section{Conclusões}

A discussão da segurança alimentar e nutrição tem ocupado posição central e frequente tanto em estudos acadêmicos como no debate de políticas de desenvolvimento (Barret, 2010). Em particular, observa-se um esforço claro no sentido de explorar as conexões entre SAN e um leque cada vez mais diverso de processos e fenômenos, como por exemplo, uso de recursos naturais (Godfray et al., 2010), mudança climática (Wheeler \& von Braun, 2013) e capital social e humano (Adair et al., 2008). Especificamente no âmbito da pesca e aquacultura, temos uma produção acadêmica crescente que adota a SAN como foco central, ou ao menos discute tópicos relacionados (Garcia \& Rosenberg, 2010; Beveridge et al., 2013). Essa literatura reflete a diversidade de temas encontrados na abordagem geral da SAN, com a adição de pontos de interesse específicos como efeitos do consumo de pescado em comunidades em países em desenvolvimento (Kawarazuka \& Béné, 2011) e estimativas do impacto da aquacultura (Tacon \& Metian, 2008). Todavia, avaliações de intervenções centradas na SAN no contexto da pesca e aquacultura são raras, com a exceção das discussões apresentadas no relatório sobre "Pesca e Aquacultura Sustentáveis para Segurança Alimentar e Nutrição" do Painel de Experts em Segurança Alimentar e Nutrição das Nações Unidas ("High Level Panel of Experts on Food Security and Nutrition, Committee on World Food Security" - HLPE (2014).

Mesmo neste caso, percebe-se que o trabalho do painel concentra-se em estabelecer uma síntese do 
conhecimento existente, apesar de oferecer recomendações para o avanço da pesquisa e adaptação de políticas e intervenções. Conforme comentado no relatório, o "pescado tem papel importante na [SAN] como fonte de alimento e renda. Ainda assim, [pesca] e aquacultura são frequentemente relegadas à margem dos debates relacionados à [SAN]." (HLPE, 2014, p. 27). O entendimento dos processos de governança, sobretudo como os conceitos de SAN e sustentabilidade são articulados em parcerias entre governo e sociedade civil é avaliado como insuficiente, com impacto desproporcional sobre populações pobres (HLPE, 2014, p. 97).

A análise crítica de iniciativas apresentadas neste artigo contribui para preencher aquela importante lacuna. Ainda que a amostra analisada seja limitada tanto por características das próprias iniciativas analisadas como pelo processo de seleção, o conjunto fornece a base empírica necessária para a avaliação da capacidade de articulação dos conceitos de SAN e redução da pobreza e a verificação de como se dá sua aplicação prática.

Nota-se primeiramente que uma parcela reduzida das potenciais intervenções podem ser genuinamente identificada como promotoras do desenvolvimento e redução da pobreza. Entre estas, observa-se uma tendência de ampla adoção da SAN e pobreza entre os objetivos das ações, que, no entanto, não se converte em aplicação prática na maior parte dos casos. Exploramos esta falta de coerência ao avaliar a aplicação dos conceitos segundo uma abordagem multidimensional da pobreza. Dessa forma, é possível descrever o nível de complexidade das abordagens, desde um foco simplificado em renda, até perspectivas que integrem vulnerabilidade e marginalização. Como consequência, identificamos como se configuram na prática ações que têm maior potencial de promover a SAN e reduzir a pobreza de forma consistente e sustentada.

O reconhecimento das múltiplas dimensões da pobreza foi limitado entre as iniciativas analisadas, o que indica a necessidade de avaliações que, mantendo o rigor conceitual aqui proposto, ampliem o universo analisado e aprofundem o processo de validação do impacto das intervenções. Nesse sentido, contribuímos de modo específico ao, por um lado, discutir em detalhe a SAN no contexto de pesca artesanal e de pequena escala e, por outro lado, estimular o debate sobre as atribuições do Estado e sociedade civil na promoção da SAN.

Demonstramos que SAN merece prioridade na discussão e prática da governança e desenvolvimento em sistemas pesqueiros: não somente há uma lacuna evidente através da análise empírica de práticas correntes, como também se observa desde um ponto de vista conceitual à possibilidade clara de conexão entre abordagens da pobreza, nutrição e gestão pesqueira sustentável. Inclusive, sugerimos um marco analítico que articula explicitamente processos de produção e segurança alimentar no contexto específico da pesca artesanal e de pequena escala.

Concluímos nossa contribuição com o questionamento dos papéis desempenhados pelos atores sociais na construção e implementação de intervenções de promoção da SAN. Esse passo final é vital, pois o processo intelectual e político que dá forma às intervenções não surge de escolhas neutras e objetivas, mas sim, é determinado por atores com variados graus de influência e que privilegiam perspectivas alinhadas com seus interesses (Long, 2001). No caso da pesca, percebe-se uma corrente particularmente influente que propõe a limitação do acesso aos recursos e a transferência de responsabilidades do Estado para sociedade civil como fundamentos para gestão pesqueira sustentável (Cunningham et al., 2009). Em princípio, o estímulo à participação da sociedade civil na governança da pesca merece apoio: conforme observado neste artigo, há uma presença estabelecida de organizações não governamentais na promoção da SAN e redução da pobreza, e o aperfeiçoamento de suas ações é uma necessidade.

Porém, destacamos que é na articulação entre Estado e sociedade civil que reside o maior potencial de desenvolvimento de intervenções efetivas. Evidências no conjunto de iniciativas analisado apontam nesta direção, assim como a revisão crítica de sucessivas formas de implementação de políticas de SAN no caso do Brasil. Nossa proposta de leitura crítica às intervenções de governança no âmbito da pesca foi capaz de esclarecer alguns pontos de reconhecida relevância, mas também tornou claro que a exploração dos processos discutidos neste artigo segue, todavia, incompleta. O uso da análise crítica dos discursos (Wodak \& Meyer, 2001) poderia 
ser particularmente útil em futuras incursões sobre o tema. Tal abordagem questiona a produção de narrativas e relações de poder, tanto na ciência como na política, e serve, conforme argumenta Escobar (1996, p. 341), como plataforma para a criação de conceitos que reorientem estratégias relacionadas ao desenvolvimento e meio ambiente na direção da justiça social.

\section{Referências}

Adair, L. S.; Fall, C. H. D.; Osmond, C.; Stein, A. D.; Martorell, R.; Ramirez-Zea, M.; Sachdev, H. S.; Dahly, D. L.; Bas, I.; Norris, S. A.; Micklesfield, L.; Hallal, P.; Victora, C. G. Associations of linear growth and relative weight gain during early life with adult health and human capital in countries of low and middle income: findings from five birth cohort studies. Lancet, 382, 525-534, 2013.

Adger, W. N. Vulnerability. Global Environmental Change, $16,268-281,2006$

Allison, E. H. Aquaculture, fisheries, poverty and food security. Working paper, 2011-65. The WorldFish Center. 62pp., 2011

Allison, E. H.; Béné, C.; Andrew, N. L. Poverty reduction as a means to enhance resilience in small-scale fisheries. In: Pomeroy, S.; Andrew, N. (Eds.). Small-scale fisheries management. Framework and approaches for the developing world. CABI, 2011

Allison, E. H.; Ellis, F. The Livelihoods Approach and Management of Small-scale Fisheries. Marine Policy, 25, 377-388, 2001

Allison, E. H.; Horemans, B. Poverty alleviation, sustainable livelihoods and management in small-scale fisheries. In: Swan, J.; Gréboval, D. (Eds.). Overcoming factors of unsustainability and overexploitation in fisheries: selected papers on issues and approaches. International Workshop on the Implementation of the International Fisheries Instruments and Factors of Unsustainability and Overexploitation in Fisheries. Siem Reap, Cambodia, 13-16 September, 2004. FAO Fisheries Report . No. 782. Rome, FAO, 2005, p. 307-338.

Allison, E. H.; Horemans, B.; Béné, C. Vulnerability reduction and social inclusion: Strategies for reducing poverty among small-scale fisherfolk. In: Paper presented at the Wetlands,

\section{Agradecimentos}

Agradecemos aos revisores anônimos pelos comentários construtivos. Esta pesquisa foi financiada pela Rockefeller Foundation. Declaração de conflito de interesses: os autores declaram não ter participação na execução de projetos ou qualquer tipo de relação formal com quaisquer das organizações citadas neste artigo.

Water and Livelihoods Workshops, Wetland International, St. Lucia, South Africa, 30 January-2 February, 2006

Allison, E. H.; Perry, A.; Badjeck, M. C.; Adger, W. N.; Andrew, N. L.; Brown, K.; Conway, D.; Halls, A.; Pilling, G. M.; Reynolds, J. D.; Dulvy, N. K. Vulnerability of national economies to potential impacts of climate change on fisheries. Fish and Fisheries, 10, 173-96, 2009

Allison, E. H.; Ratner, B. D.; Asgard, B.; Willmann, R.; Pomeroy, R.; Kurien J. Rights-based fisheries governance: from fishing rights to human rights. Fish and Fisheries, 13(1), $14-29,2012$

Arruda, B. K. G.; Arruda, I. K. G. Marcos referenciais da trajetória das políticas de alimentação e nutrição no Brasil. Revista Brasileira de Saúde Maternal e Infantil, 7(3), 319-326, 2007.

Barret, C. B. Measuring Food Insecurity. Science, 327, 825828,2010

Bavinck, M. Understanding Fisheries Conflicts in the South - A Legal Pluralist Perspective. Society \& Natural Resources, 18(9), 805-820, 2005.

Bavinck, M.; Chuenpagdee, R.; Diallo, M.; van der Heijden, P.; Kooiman, J.; Mahon, R.; Williams, S. Interactive fisheries governance - A guide to better practice. Delft: Eburon Academic Publishers, 2005.

Bebbington, A. Capitals and Capabilities: A Framework for Analyzing Peasant Viability, Rural Livelihoods and Poverty. World Development, 27(12), 2021-2044, 1999.

Béné, C. When fishery rhymes with poverty, a first step beyond the old paradigm on poverty in small-scale fisheries. World Development, 36, 945-75, 2003. 
Béné, C. Are fishers poor or vulnerable? Assessing economic vulnerability in small-scale fishing communities. Journal of Development Studies, 45, 911-33, 2009.

Béné, C.; Friend, R. M. Poverty in small-scale fisheries: Old issue, new analysis. Progress in Development Studies, 11(2), 119-144, 2011.

Béné, C.; Hersoug, B.; Allison, E. H. 'Not by rent alone': analyzing the pro-poor functions of small-scale fisheries in developing countries. Development Policy Review, 28(3), 325-358, 2010.

Béné, C.; Macfadayen, G.; Allison, E. H. Increasing the contribution of small-scale fisheries to poverty alleviation and food security. Fisheries and Aquaculture Technical Papers 481. FAO, Rome. 141 pp., 2007

Béné, C.; Neiland, A. E. From Participation to Governance: A critical review of the concepts of governance, co-management and participation, and their implementation in small-scale inland fisheries in developing countries. WorldFish Center Contribution No. 1750., 2006

Berkes, F.; Mahon, R.; McConney, P.; Pollnac, R.; Pomeroy, R. Managing Small-scale Fisheries Alternative Directions and Methods. IDRC, Ottawa, Canada, 2001

Beveridge, M. C. M.; Thilsted, S. H.; Phillips, M. J.; Metian, M.; Troell, M.; Hall, S. J. Meeting the food and nutrition needs of the poor: the role of fish and the opportunities and challenges emerging from the rise of aquaculture. Journal of Fish Biology, 83, 1067-1084, 2013.

Bhutta, Z. A.; Das J. K.; Rizvi A.; Gaffey, M. F.; Walker, N.; Horton, S.; Webb, P.; Alartey, A.; Black, R. E. Evidence-based interventions for improvement of maternal and child nutrition: what can be done and at what cost? Lancet, 382, 452-477, 2013.

Black, R. E.; Allen, L. H.; Bhutta, Z. A.; Caulfield, L.E.; de Onis, M.; Ezzati, M.; Mathers, C.; Rivera, J. Maternal and child undernutrition: global and regional exposures and health consequences. Lancet, 371, 243-260, 2008.

Blaikie, P. Is Small Really Beautiful? Community-based Natural Resource Management in Malawi and Botswana. World Development, 34(11), 1942-1957, 2006.

Castro J. Geografia da Fome: o dilema brasileiro: pão ou aço. Rio de Janeiro: Civilização Brasileira, 2001.

CEA - California Environmental Associates. Charting a Course to Sustainable Fisheries. California Environmental Associates, San Francisco, CA., 2012.
CGIAR. Research Program on Aquatic Agricultural Systems. Program Proposal, Penang, Malaysia. AAS-2012-07, 2012.

Charles, A. T. Fishery conflicts. Ecological Economics, 379393, 1992

Chuenpagdee, R.; Liguori, L.; Palomares, M. L. D.; Pauly, D. Bottom-up, Global Estimates of Small-Scale Marine Fisheries Catches. Fisheries Centre Research Reports 14(8). Fisheries Centre, University of British Columbia, Vancouver, Canada, 105 pp, 2006

Coulthard, S.; Johnson, D.; McGregor, A. Poverty, sustainability and human wellbeing: a social wellbeing approach to the global fisheries crisis. Global Environmental Change, 21, 453-463, 2011.

Cunningham, S.; Neiland, A. E.; Arbuckle, M.; Bostock, T. Wealth-based Fisheries Management: Using Fisheries Wealth to Orchestrate SoundFisheries Policy in Practice. Marine Resource Economics, 24, 271-287, 2009

de la Rocha, M. G.; Jelin, E.; Perlman, J.; Roberts, B.; Safa, H.; Ward, P. M. From the marginality of the 1960s to the "new poverty" of today: A LARR Research Forum. Latin American Research Review, 39(1), 183-203, 2004.

de Schutter, O. Interim Report of the special rapporteur on the right to food. United nations General Assembly A/67/268, 2012

Dercon, S. Vulnerability: a micro perspective. University of Oxford. Annual Bank Conference on Development Economics, Amsterdam, The Netherlands May, 23-24, 2005. The World Bank. Disponível em: <http://siteresources.worldbank.org/ intamsterdam/Resources/StefanDercon.pdf $>$

Ellis, F. Small-Farms, Livelihood Diversification and RuralUrban Transitions: Strategic Issues in Sub-Saharan Africa. Paper prepared for the Research Workshop on: The Future of Small Farms. International Food Policy Research Institute (IFPRI) Overseas Development Institute (ODI), Imperial College, London. 2005.

Escobar, A. Construction Nature: Elements for a post-structuralist ecology. Futures, 28(4), 325-343, 1996.

FAO. International guidelines for securing sustainable smallscale fisheries. Zero draft, May, 2012. Disponível em: http:// www.fao.org/fishery/ssf/guidelines/en

Fussel, H-M. Vulnerability: A generally applicable conceptual framework for climate change research. Global Environmental Change, 17, 155-167, 2007.

Garcia, S. M.; Rosenberg, A. A. Food security and marine capture fisheries: characteristics, trends, drivers and future 
perspectives. Philosophical Transactions of the Royal. Society. B-Biological Siences, 365, 2869-2880, 2010.

Gillespie S.; Haddad, L.; Mannar, V.; Menon, P.; Nisbett, N. Maternal and Child Nutrition Study Group. The politics of reducing malnutrition: building commitment and accelerating progress. Lancet, 382, 552-569, 2013.

Godfray, H. C. J.; Beddington, J. R.; Crute, I. R.; Haddad, L.; Lawrence, D.; Muir, J. F.; Pretty, J.; Robinson, S.; Thomas, S. M.; Toulmin, C. Food Security: The Challenge of Feeding 9 Billion People. Science, 327, 812-818, 2010.

Haimovici, M.; Vasconcellos, M.; Kalikoski, D. C.; Abdallah, R. P.; Castello, J. P.; Hellebrandt, D. Diagnostico da pesca no Rio Grande do Sul. In: Isaac, V.; Martins, S. A.; Haimovici, M.; Andriguetto-Filho, J. M. (Org.). A Pesca Marinha e Estuarina do Brasil no Início do Século XXI: recursos, tecnologias, aspectos socio-economicos e institucionais. UFPA, Belem, pp. 157-180, 2006.

HCLME - Humboldt Current Large Marine Ecosystem Towards Ecosystem Based Management Chile - Peru GEF- PIMS 4147 Inception Report, 2012.

HLPE. Sustainable fisheries and aquaculture for food security and nutrition. A report by the High Level Panel of Experts on Food Security and Nutrition of the Committee on World Food Security, Rome, 2014.

Jentoft, S. Institutions in fisheries: what they are, what they do, and how they change. Marine Policy, 28, 137-149, 2004.

Jentoft, S.; McCay, B. J.; Wilson, D. C. Social theory and fisheries co-management, Marine Policy, 22, 423-436, 1998.

Johnson, D. S. Category, narrative, and value in the governance of small-scale fisheries. Marine Policy, 30, 747-756, 2006.

Kawarazuka, N,; Béné, C. The potential role of small fish species in improving micronutrient deficiencies in developing countries: building evidence. Public Health Nutrition, 14, 1927-1938, 2011.

Kooiman, J.; Bavinck, M.; Chuenpagdee, R.; Mahon, R.; Pullin, R. Interactive Governance and Governability: An Introduction. The Journal of Transdisciplinary Environmental Studies, 7(1), 2008.

Lomnitz, L A. Informal Exchange Networks in Formal Systems: A Theoretical Model. American Anthropologist, New Series, 90(1), 42-55, 1988.

Long, N. Development sociology: actor perspectives. London: Routledge, 2001
Macfadyen, G.; Corcoran, E. Literature review of studies on poverty in fishing communities and of lessons learned in using the sustainable livelihoods approaches in poverty alleviation strategies and projects. FAO Fisheries Circular No. 979, Food and Agriculture Organisation, 2002

Masset E.; Haddad L.; Cornelius A.; Izara-Castro, J. Effectiveness of agricultural interventions that aim to improve nutritional status of children: systematic review. BMJ, 344, d8222, 2012.

Narayan, D.; Chambers, R.; Shah, M. K.; Petesch, P. Voices of the Poor: Crying Out for Change. New York, N Y: Published for the World Bank, Oxford University Press, 2000.

Nascimento, R. C. A fome como uma questão social nas políticas públicas brasileiras. Revista IdeAS - Interfaces em Desenvolvimento, Agricultura e Sociedade, 3(2), 197-225, 2009.

Oliveira, F. de. A economia brasileira: crítica à razão dualista. Estudos CEBRAP, 2: 5-82, 1972.

Ostrom, E.; Burger, J.; Field, C.B.; Norgaard, R.B.; Policansky, D. Revisiting the Commons: Local Lessons, Global Challenges. Science. 284, 278-282. 1999.

Pinheiro, A. R. O.; Carvalho, M. F. C. C. Transformando o problema da fome em questão alimentar e nutricional: uma crônica desigualdade social. Ciência e Saúde Coletiva, 15(1), 121-130, 2010

Pinstrup-Andersen, P. Food security: definition and measurement. Food Security, 1, 5-7, 2009.

Pinstrup-Andersen, P. Nutrition-sensitive food systems: from rhetoric to action. Lancet Vol. 382 375-376, 2013.

Portes, A. Economic sociology: a systematic enquiry. Princeton University Press, 2010.

Portes, A.; Roberts, B. R. The Free-Market City: Latin American Urbanization in the Years of the Neoliberal Experiment. Studies in Comparative International Development, Vol. 40, No. 1, pp. 43-82, 2005

Ratner, B. D.; Allison, E. H. Wealth, rights, and resilience: an agenda for governance reform in small-scale fisheries. Development Policy Review, 30(4), 371-398, 2012.

Rosegrant, M. W.; Cline, S. A. Global Food Security: Challenges and Policies. Science, 302, 1917-1919, 2003.

Sharma, C. Sustainable Small-scale Fisheries: Towards FAO Guidelines on Marine and Inland Small-scale Fisheries. International Collective in Support of Fishworkers (ICSF). Workshop and Symposium Report. 19-21, September, 2011 Kolkata, West Bengal, India. Edited by KG Kumar., 2011. 
Sen, A. Poverty and Famines: An Essay on Entitlement and Deprivation. Oxford University Press, Oxford, 1981.

Silva, A. C. De Vargas a Itamar: políticas e programas de alimentação e nutrição. Estudos Avançados, 9(23), 1995.

Subasinghe, R. P.; Arthur, J. R.; Bartley, D. M.; De Silva, S. S.; Hishamunda, N.; Mohan, C. V.; Sorgeloos, P. Farming the Waters for People and Food. Proceedings of the Global Conference on Aquaculture. Phuket, Thailand, September, 2010. FAO and NACA. 910Pp, 2012.

Tacon, A. G. J.; Metian, M. Global overview on the use of fish meal and fish oil in industrially compounded aquafeeds: Trends and future prospects. Aquaculture, 285, 146-158, 2008.

Turner, B. L.; Kasperson, R. E.; Matson, P. A.; McCarthy, J. J.; Corell, R. W.; Christensen, L.; Eckley, N.; Kasperson, J. X.; Luers, A.; Martello, M. L.; Polsky, C.; Pulsipher, A.; Schiller, A. A framework for vulnerability analysis in sustainability science, Proceedings of the National Academy of Sciences of the United States of America, 100, 8074-8079, 2003.

UNDP - United Nations Development Programme. Pescado Azul Women's Association of Isabela, Ecuador. Equator Initiative Case Study Series. New York, NY, 2012.

Wheeler, T.; von Braun, J. Climate Change Impacts on Global Food Security. Science, 341, 508-513, 2013.

Wilson, J. Scientific uncertainty, complex systems, and the design of common-pool institutions. In: Ostrom, E.; Dietz, T.; Dolsak, N.; Stern, P. C.; Stonich, S.; Weber, E. U. (Eds.). The Drama of the Commons. Committee on the Human Dimensions of Global Change. National Research Council. National Academy of Sciences. 2002, p. 327-359.

Wodak, R.; Meyer, M. Methods of Critical Discourse Analysis. Introducing Qualitative Methods. Sage., 2001.

\section{ANEXO}

\section{Descrição detalhada da estratégia de busca e consulta direta (texto original extraído do relatório final do projeto)}

\section{Assessing interventions that try to support food security and poverty reduction}

In the following section we will use the generic word 'intervention' to refer to a project, program, initiative, solution.

In the first phase of the study approach, two activities focused on identifying interventions to understand the mechanisms that address poverty reduction and food security and their determinants for success.

\section{Activity 1:}

We prepared an email with specific details and instructions regarding the project goal and search. The email was first sent to a list of professional contacts by each author, and in some cases was forwarded to other networks by those initial contacts.

The email was specific in its instruction that this study was interested in:

- developing and transitional countries

- initiatives having an explicit aim of contributing to poverty reduction and/or food security and was not interested in:

- Projects that were exclusively or primarily concerned with research or advisory outputs 


\section{Activity 2:}

The team conducted a web search of innovative initiatives in Latin America/Caribbean, Africa and Asia-Pacific. The focus was on conservation and development and looked at transformative interventions. The following table provides details on the different sources used:

\begin{tabular}{|l|l|}
\hline Source & Search terms or comments \\
\hline Google & $\begin{array}{l}\text { Fisheries, coastal livelihood, marine conservation AND food security, poverty, } \\
\text { human rights, empowerment, sustainability, gender, health AND project, pro- } \\
\text { gram }\end{array}$ \\
\hline RARE database & $\begin{array}{l}\text { Searched for "solutions" that explicitly mention 'poverty reduction' and/or } \\
\text { 'food security' in the description. Also used to cross check which interventions } \\
\text { appear in both databases. Rare searches the globe for replicable, sustainable } \\
\text { environmental success stories. 4 projects were found in both databases }\end{array}$ \\
\hline $\begin{array}{l}\text { Extended networking (ICSF, IIFET, WIOMSA, }, \\
\text { CTPC, TBTI) }\end{array}$ & $\begin{array}{l}\text { From experience and advice from other colleagues we strived to find initia- } \\
\text { tives that were also concerned with private-public partnerships, cooperatives, } \\
\text { campaigns and other relevant issues that were not represented in our database } \\
\text { so far. }\end{array}$ \\
\hline Other databases focused on similar interventions & $\begin{array}{l}\text { Other organizations such as BoP, Synchronicity Earth are currently working on } \\
\text { similar methods but with a different approach/focus/lens. These were scanned } \\
\text { for potential innovative interventions that would fit in our database. We also } \\
\text { looked at interventions listed in award competitions organized by different or- } \\
\text { ganizations, charity trusts that are rewarding conservation/sustainable develop- } \\
\text { ment initiatives (same method used as for RARE database above). }\end{array}$ \\
\hline
\end{tabular}

\section{Activity 3:}

Once all interventions were systematically listed, we developed a series of criteria for selection of relevant interventions, as follows:

- Countries that are classified as developing according to the UNCTAD or countries that are in transition according to the IMF list;

- Interventions that have an explicit aim of contributing to poverty reduction and/or food security. In this first selection criteria we will only look at project that either:

- Clearly state in their mission/objectives that the project aims at reducing poverty and/or improving food security

- Refer to the definition of food security: "when all people, at all times, have physical, social and economic access to sufficient, safe and nutritious food that meets their dietary needs and food preferences for an active and healthy life"

- Refer to at least one dimension of poverty that relate to human capabilities including consumption and food security, health, education, rights, voice, security, dignity and decent work.

- Interventions that take any action whether political, social, economic, institutional or environmental. This excludes interventions exclusively or primarily concerned with research or advisory outputs. 


\section{Consultation with stakeholders}

To ensure that our survey was informed by current policy discussions we identified a number of opportunities for consultation with relevant stakeholders in Africa, Asia and Latin America and the Caribbean. Thus, we attended the following events:

$>$ Consultation with marine conservation and private sector actors at the World Seafood Summit, Hong Kong, September 6-8 th, 2012. We were able to identify organizations working with small-scale producers in developing countries and to evaluate the extent to which partnerships between international conservation organizations and major private sector actors were addressing concerns around food security and poverty reduction in the fisheries sector.

$>$ Presentation on food security and fisheries to FAO Fisheries Division in Rome (September , 20 th, 2012); participation in a meeting of the FAO Small-scale fisheries task force (December

13 th, 2012); collaboration with an FAO-led consultation of cooperatives in fisheries

(comments on study design, September, 2012; response to questionnaire, November, 2012).

$>$ Direct consultation with fisheries experts and development practitioners working in Latin America and the Caribbean while attending the 65 th annual meeting of the Gulf and Caribbean Fisheries Institute, held in Santa Marta, Colombia, November 5-9 th, 2012 . We benefited from a series of simultaneous events held during the 65 th GCFI meeting, in which the "Too Big To Ignore" (TBTI) network promoted debates and networking among experts and practitioners in small-scale fisheries in the region. Finally, we were also able to consult with a group of fishers attending the event (representatives of the Virgin Islands fishers association). The outcome of these consultations was a confirmation of an accurate identification of key initiatives in the region in collaboration with people directly involved or close to those initiatives (for example, COBI in Mexico, Praia do Canto Verde fishers association in Brazil). 